Dept. of Surgery, Anesthesiology and Radiology,

Fac. Vet. Med., Suez Canal Univ.

\title{
STUDIES ON THE EFFECT OF MEDETOMIDINE VERSUS ROMIFIDINE IN BUFFALO CALVES
}

(With One Table and 12 Figures)

By

\author{
M.H. SHEKIDEF; A.M. AL-AKRAA* \\ and M.M. GHANEM**
}

*Dept. of Surgery, Fac. Vet. Med. Benha Univ.

**Dept. Medicine, Fac. Vet. Med. Benha Univ.

(Received at 16/6/2007)

\section{دراسات على تأثير الميديتوميدين والروميفيدين فى عجول الجاموس محد حسن شقبإف ، عادل محمد الأفرع ، محمد محدى غانم}

أجريت هذه الدراسة على خمسة من عجول الجاموس فى دراسة تبادلية مع فترة بينية مدتها ثثلاثة أسابيع. في المجموعة الأولى، تم حقن الخمسة عجول فئ في الوريد بعقار الميدينوميدين بجرعة • 1 ميكجم/كجم؛ بينما تم حقن نفس الحيوانات بعد ثناثة أسابيع بعقار الروميفيدين

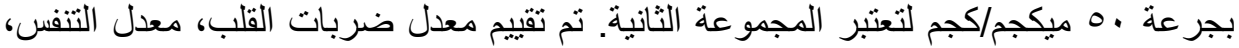
درجة التهدئة، درجة ارتخاء العضلات، رد رد الفحل الإصبعي والوخذى قبل الحقن و عند الأوقات

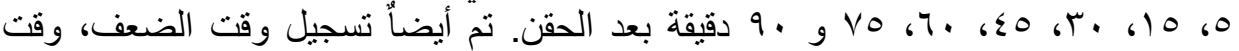

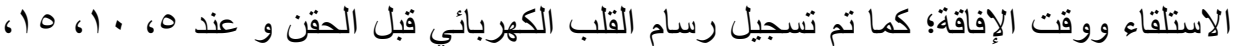

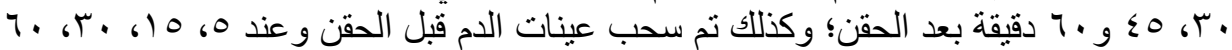

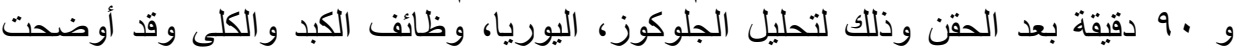

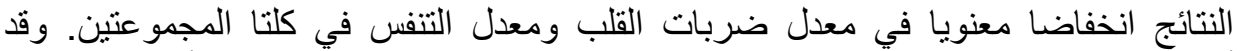
أوضح رسام القلب الكهربائي اتساع نطاق ال R, T waves في المجمولي عة الأولى بينما كان

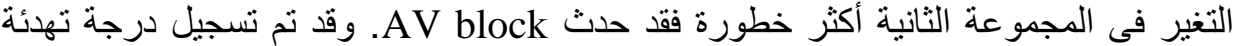
متوسطة ودرجة ارتخاء وكذلك درجة غياب للإحساس طفيفة في المجمو عتين. كما أثبتت

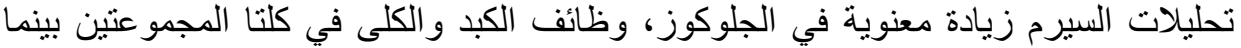

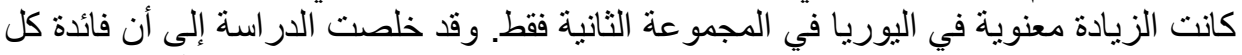

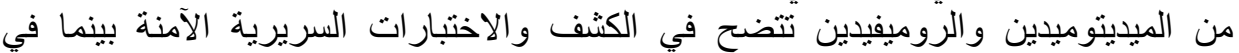

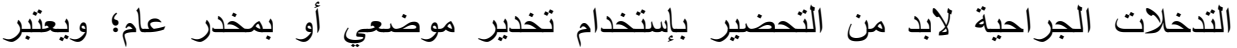

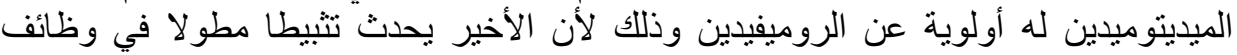

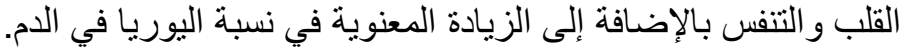

\section{SUMMARY}

Five healthy buffalo calves were used in this study in a crossover design with an interval of three weeks. In group I, the five calves received me- 
detomidine $10 \mu \mathrm{g} / \mathrm{kg}$ intravenously while in group II, the same five calves, after three weeks, were injected i.v. with romifidine $50 \mu \mathrm{g} / \mathrm{kg}$. The calves were evaluated at baseline and then at 5, 15, 30, 45, 60, 75 and 90 minutes after drug administration for respiratory rate, heart rate, degree of sedation, muscle relaxation, and response to pedal and pinprick reflexes. Weak time, down time and recovery time were recorded in both groups. ECGs were recorded in all animals at baseline, $5,10,15,30,45$ and 60 min post-injection. Blood samples were taken at baseline, 5, 15, 30, 60 and 90 minutes after drug administration for determination of serum glucose, urea, AST, LDH and CPK. Heart rate decreased significantly in both groups. ECG findings in group I revealed increase in the amplitude of $\mathrm{R}$ wave and $\mathrm{T}$ waves became monophasic and had higher amplitude while in group II there was an atrioventricular (AV) heart block. Moderate sedation, mild muscle relaxation and mild analgesia were recorded in both groups. There was significant increase in serum glucose in both groups, while group II only showed significant increase in serum urea. Serum AST, LDH and CPK increased significantly in both groups compared to baseline values. It could be concluded that medetomidine and romifidine are considered beneficial for safe investigation and clinical examination in buffalo calves but further restraint or conjunction with other local or general anesthetic is needed for surgical approaches. However, medetomidine is considered superior to omifidine because the later induces prolonged cardiopulmonary depression and comparatively higher serum levels of urea and cardiac enzymes.

Key words: Medetomidine, romifidine, buffalo calves.

\section{INTRODUCTION}

The $\alpha 2$-adrenoceptor agonists ( $\alpha 2$-agonists) are popular in veterinary and human medicine for use as anxiolytics, analgesics, and preanesthetic sedatives (Kastner, 2006). He added that, in veterinary practice, the relatively new $\alpha 2$-agonist, (4-[1-(2, 3-dimethylphenyl) ethyl]-1H-imadazole) hydrochloride (medetomidine), is widely used for sedation and to reduce the general anesthetic requirement. Medetomidine is the most selective $\alpha_{2}$-agonist used in veterinary medicine and produces sedation and analgesia in dogs (Malm, Strandberg, Danell, Audell, Swenson, and Hedhammar, 2007), in goats (Kinjavdekar, Singh, Amarpal, Aithal, and Pawde, 2007), in the cat (Westropp, Kass, and Buffington, 2007), and in horses (Umar, Yamashita, Kushiro, and Muir, 2007). 
Romifidine is an imino-imidazolidine derivative, selective and a new $\alpha 2$-adrenoceptor agonist drug that is mostly administered systemically to bring about sedation and analgesia in sheep (Celly, McDonell, Young, and Black, 1997; and Kastner, 2006), dogs (Gomez-Villamandos, Redondo, Martin, Dominguez, Granados, Estepa, Ruiz, Aguilera, and Santisteban, 2005), horses (Figueiredo, Muir, Smith, and Wolfrom, 2005), and spinally in goats (Kinjavdekar, Aithal, Amarpal, Pawde, Pratap, and Singh, 2006; and Kinjavdekar, et al. 2007). Few studies, if any, had been performed to evaluate the effects of the IV injection of medetomidine or romifidine in buffaloes.

The objective of this study was to assess and compare the analgesic, sedative, and cardiopulmonary effects of intravenous injection of medetomidine versus romifidine in buffalo calves.

\section{MATERIALS and METHODS}

\section{Animals}

Five healthy buffalo calves of both sex (three males and two females), 12- 18 months of age weighing 110-150 kg were used in this study in a crossover design with an interval of three weeks. The buffalo calves were kept in a controlled environment and maintained under uniform managerial practice for feeding, watering and housing in the educating farm of the Faculty of Veterinary Medicine, Benha University. The food was withheld for at least 24 hours prior to experimentation. The animals were restrained with thick cotton ropes during the experiment.

\section{Drugs}

The dosages of medetomidine and romifidine were selected on the basis of a pilot study conducted on three buffalo calves guided with doses cited in the previous literatures. The drugs and their dosages used in this study were as follows. In group I, the five calves received medetomidine (Domitor ${ }^{\circledR}, 1 \mathrm{mg} / \mathrm{ml}$, Pfizer Pharma GmbH) $10 \mu \mathrm{g} / \mathrm{kg}$ intravenously (i.v.). In group II, the five calves, after three weeks, were injected i.v. with romifidine (Sedivet $10 \mathrm{mg} / \mathrm{ml}$, Boehringer Ingelheim, Burlington, ON, Canada) $50 \mu \mathrm{g} / \mathrm{kg}$.

\section{Evaluation of sedation}

The sedation induced by medetomidine (group I) was compared with that induced by romifidine (group II) using five buffalo calves in each group. Each animal was injected i.v. with the two agents with three weeks interval in a crossover design. After recording the baseline values (pre-induction) of respiratory rate, and heart rate, as well as, ECG 
tracing using an ECG monitor (Fukuda Denshi Co., Ltd. Tokyo, Japan) and taking a blood sample, medetomidine and romifidine were administered to animals of group I, and group II respectively. The buffalo calves were evaluated at time 0 (pre-induction) and then at 5, 15, $30,45,60,75$ and 90 minutes after drug administration for respiratory rate, and heart rate, as well as, degree of sedation, muscle relaxation, and response to pedal and pinprick reflexes. Scores awarded to the later four parameters were according to Pawde, Amarpal, Kinjavdekar, Aithal, Pratap and Bisht (2000) as follows: pedal reflex (score 0-3): 0, intact; 1, weak; 2, very weak; 3, abolished; response to pinprick (score 0-3): 0 , strong; 1, weak; 2, very weak; 3 , abolished; muscle relaxation (score 0-3): 0, absent (tightly closed jaws and stiff limbs); 1, mild (moderate resistance to opening of jaws and bending of limbs); 2, moderate (mild resistance to opening of jaws and bending of limbs); 3 , complete (no resistance to opening of jaws, bending of limbs and flaccid abdomen); sedation (score 0-3): 0, no sedation (standing alert, keeping the head high, eyes open); 1, mild (standing tired, lowering of head, drooping of eye lids); 2, moderate (recumbent but able to sit without support); 3 , strong (unable to sit without support).

Weak time was the time (minutes) elapsed from the time of injection of the drug to the time when the animal showed ptosis of the head. Down time was the time from the administration of medetomidine or romifidine to sternal/lateral recumbency. Recovery time was recorded in both groups as the time elapsed between the time of administration of drugs and the time when the animal was able to walk unassisted. Muscle relaxation was observed in the muscles of abdomen, legs and jaws. The ease with which the jaws of recumbent animals could be operated and their hind limbs could be bent without resistance, as well as the flaccid abdomen could be pressed was recorded as the extent of muscle relaxation according to Sharma, Kumar, Dimri, Hoque, Maiti, Gupta, and Shahi, (2004).

ECG traces were recorded in all animals of both groups using lead II and ECG Monitor (Fukuda Denshi Co., Ltd. Tokyo, Japan) at 0 (pre-injection), 5, 10, 15, 30, 45 and 60 minutes post-injection. Briefly, the right forelimb electrode (RA) and the left forlimb electrode (LA) were attached to the right and left elbow joints, respectively through needles inserted into these areas (Fig. 1). Both hind limb electrodes (RL and LL) were attached to the skin over the right and left stifle joint. The R-R interval was calculated as an indicator of the cardiac frequency (Huber, Neagu, Braslasu, Braslasu, and Joita, 2004). 


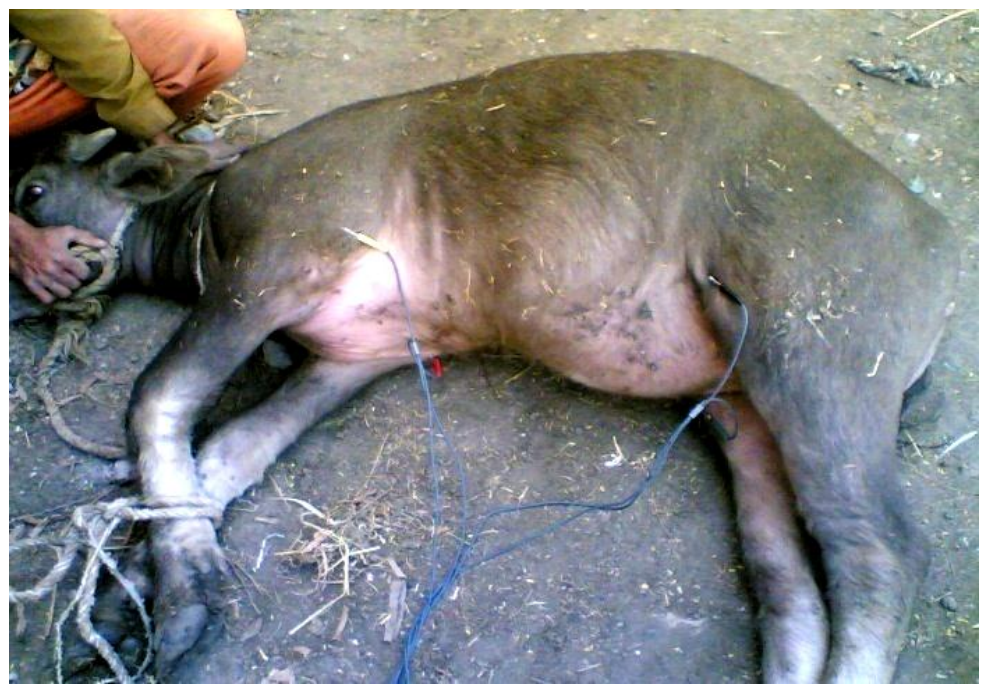

Fig. 1: The figure of electrodes positioning for measuring of a baseline Lead II ECG tracing in a buffalo calf before injection of medetomidine.

Blood samples were collected from jugular vein at 0 (pre-induction) and then at 5, 15, 30, 60 and 90 minutes after drug administration for determination of serum glucose, urea, AST, LDH and CPK.

\section{Statistical analysis}

The changes of heart rate and respiratory rate, as well as, serum biochemical values were compared with their baseline values using one way ANOVA. In addition, weak time, down time and recovery time in the two groups were also compared using one way ANOVA and means were compared using Duncan's multiple range test. A subjective scoring system of sedation, muscle relaxation and pedal and pinprick reflexes was used and data from calves of group I and II were compared by Wilcoxon's signed ranks test $(\mathrm{P}<0.05$ considered significant). The statistical analyses were all performed using SPSS (version 13 for windows; SPSS Inc., Chicago, IL. USA).

\section{RESULTS}

Heart rate decreased significantly in both groups (Fig. 2). The fall in heart rate in group II was greater than that of group I as compared to the baseline values. In group I, the fall in heart rate was significant up to 75 minutes after injection of medetomidine, while at 90 minutes after 
its injection, heart rate had become non significantly changed from the baseline value. In group II, the fall in heart rate was significant all over the study period.

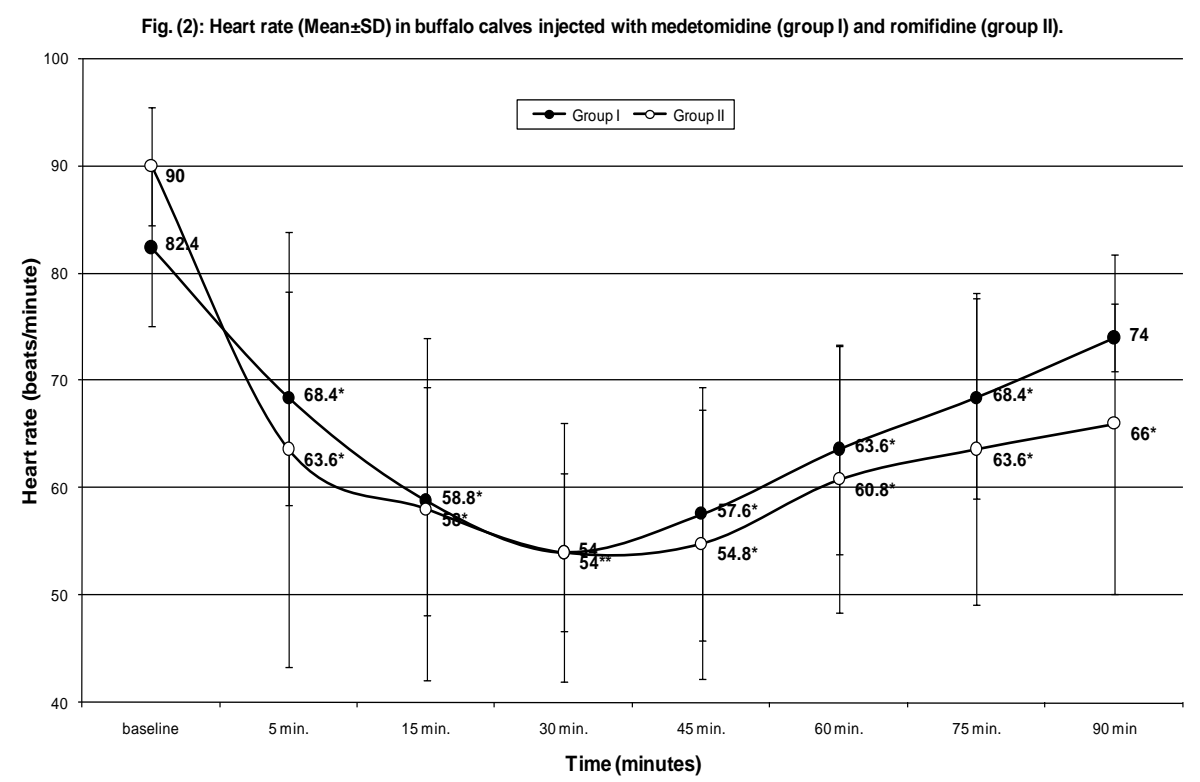

ECG findings (Fig. 3) of medetomidine-injected buffalo calves showed a marked reduction in the heart rate (bradycardia) denoted by prolongation of the R-R interval (the period between 2 successive $\mathrm{R}$ waves) (Fig. 4). The myocardial contraction increased markedly as denoted by the increase in the amplitude of $\mathrm{R}$ wave starting at 5 minutes post-injection. The normal biphasic (bifid) $\mathrm{P}$ wave became monophasic. Moreover, the $\mathrm{T}$ waves became monophasic instead of biphasic and had higher amplitude. The ventricles began to return to their normal contraction, heart rate began to return to its baseline value and the biphasic $\mathrm{P}$ wave returned to its normal figure 60 minutes after injection.

ECG findings, in group II, showed bradycardia accompanied by first and second degree of atrioventricular (AV) heart block. The AV block appeared as that the $\mathrm{P}$ waves were not followed by QRS or T waveforms. This figure indicated that the impulses did not transmit from atria to ventricles. The heart block continued even beyond 60 minutes after injection of romifidine (Fig. 3). 


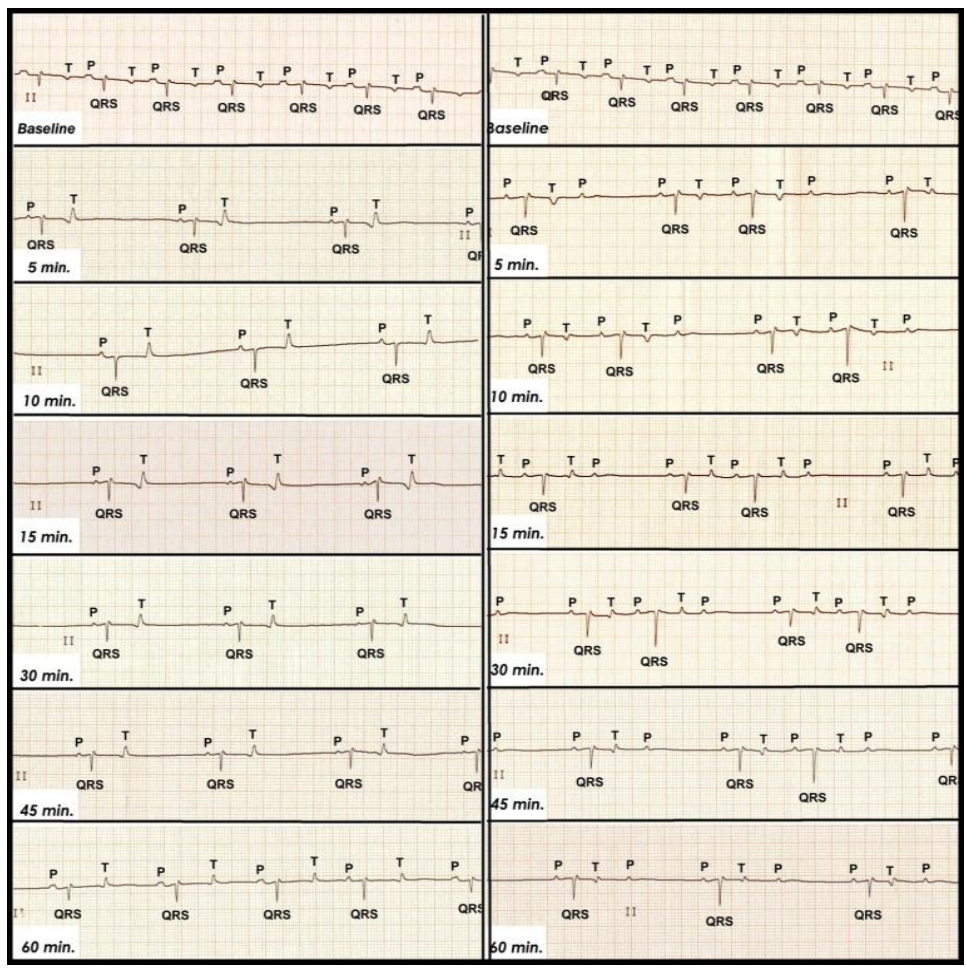

Fig. 3: Lead II ECG tracing of a buffalo calf from group I, injected with medetomidine (Left column), and a buffalo calf from group II, injected with romifidine (Right column). The tracings were recorded before (baseline) and after injection in different time series.

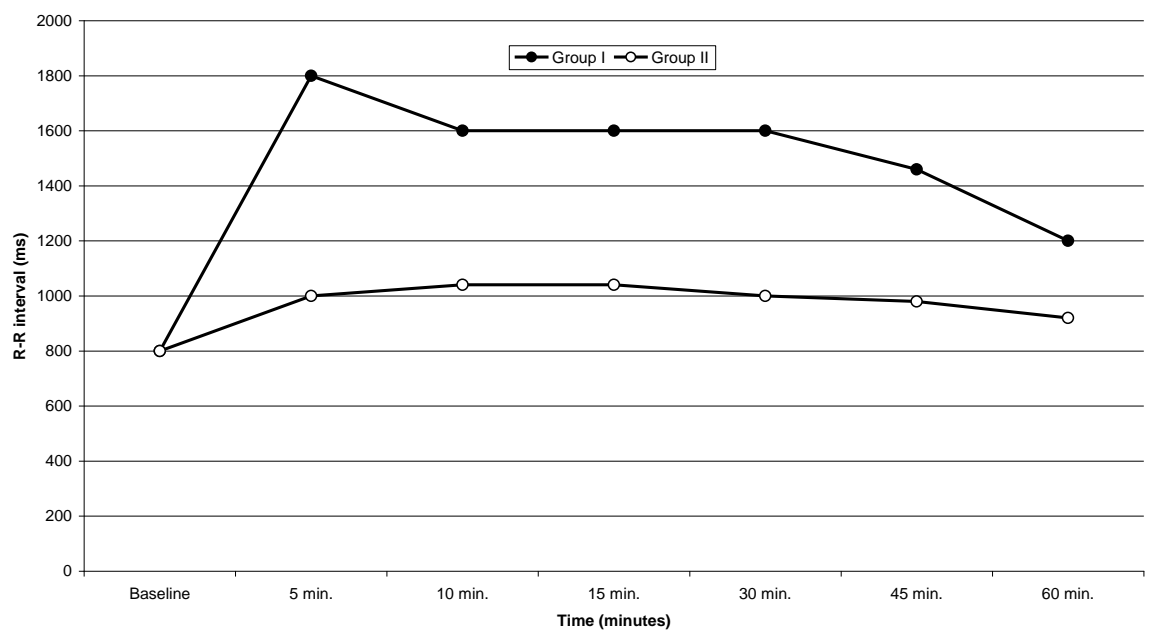


Respiratory rate (Fig. 5) decreased significantly at 15, 30 and 45 minutes after medetomidine injection in group I, while it decreased significantly at 5, 15, 30, 45, 60 and 75 minutes after romifidine injection in group II.

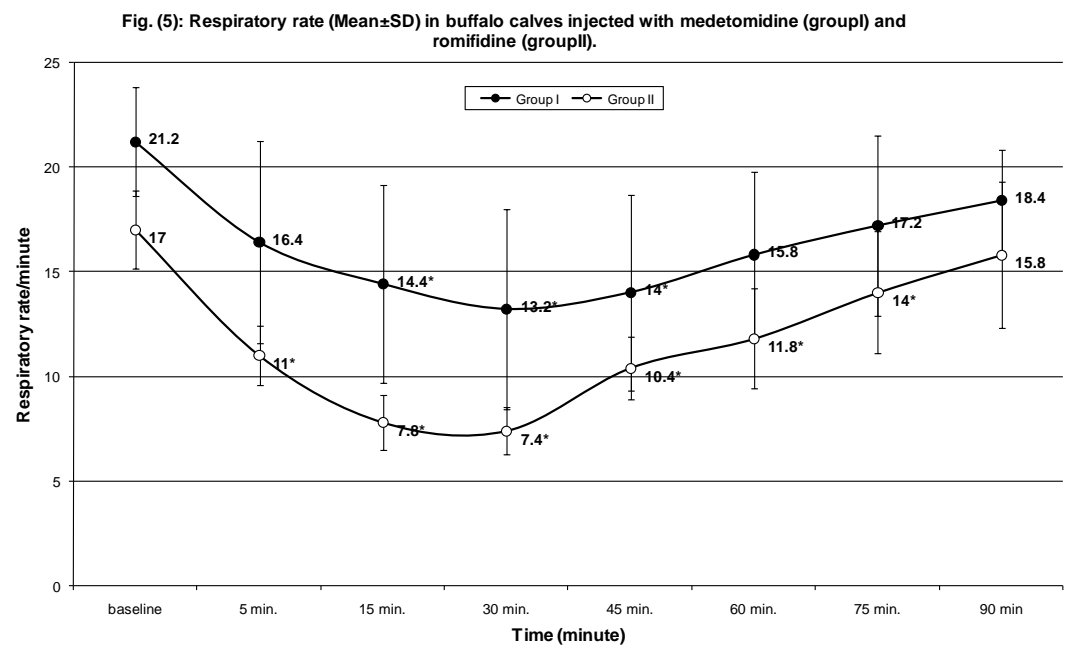

In group I, the mean weak time (5.8 minutes) and down time (9 minutes) were non-significantly higher than the weak time (3 minutes) and down time (6.4 minutes) in group II respectively. Recovery time (108 minutes), after romifidine sedation, was significantly longer than that after medetomidine sedation (71 minutes) (Fig. 6). All animals of both groups took the same sternal recumbent position resembles to the milk fever position with head and neck deviated laterally.

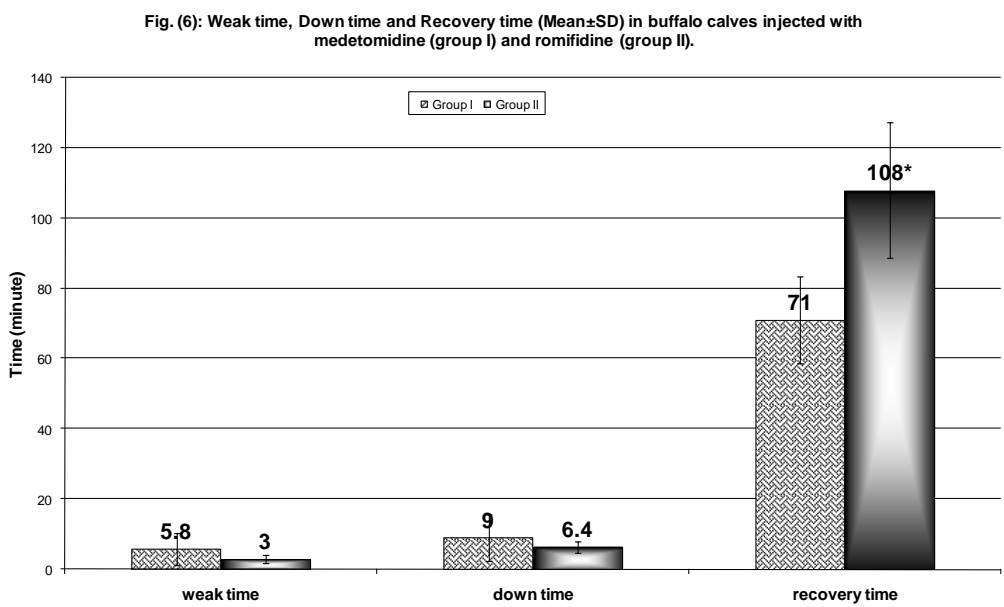


There was no significant difference in the degree of sedation (Table, 1) between the two groups allover the study period $(\mathrm{P}>0.05)$. Moderate sedation was recorded in all except one animal after injection of medetomidine and romifidine. These animals showed sternal recumbency and took a position resemble to the milk fever position allover the period from 15 - 60 minutes after injection (Fig. 7 A\&B), thereafter mild sedation followed the deep sedation for another 15 minutes and the calves were standing tired and their heads were lowered (Fig. 7 C\&D). Only one animal from five administered with medetomidine showed a deeper degree of sedation than other animals. This calf was laterally recumbent and unable to sit without support for 60 minutes after medetomidine injection; thereafter it began to sit on sternal recumbent position for another 20 minutes. Although the degree of sedation was moderate in the two groups without significant difference, romifidine induced longer and slightly deeper sedation than did medetomidine. Excessive salivation was observed in all animals allover the period of sedation.

Table 1: Difference between romifidine-medetomidine (Wilcoxon's signed ranks tests) in degree of sedation, muscle relaxation, pedal and pinprick reflexes (mean ranks and P-value).

\begin{tabular}{|c|c|c|c|c|c|c|c|c|c|c|c|c|}
\hline \multirow{3}{*}{ Time } & \multicolumn{3}{|c|}{ Degree of sedation } & \multicolumn{3}{|c|}{ Muscle relaxation } & \multicolumn{3}{|c|}{ Pedal reflex } & \multicolumn{3}{|c|}{ Pinprick reflex } \\
\hline & \multicolumn{2}{|c|}{ Mean rank } & \multirow{2}{*}{$\mathrm{P}$ - value } & \multicolumn{2}{|c|}{ Mean rank } & \multirow[t]{2}{*}{$\mathrm{P}$ - value } & \multicolumn{2}{|c|}{ Mean rank } & \multirow[t]{2}{*}{ P-value } & \multicolumn{2}{|c|}{ Mean rank } & \multirow[t]{2}{*}{ P-value } \\
\hline & $-\mathrm{ve}$ & +ve & & -ve & $+\mathrm{ve}$ & & -ve & +ve & & -ve & $+\mathrm{ve}$ & \\
\hline Baseline & 0 & 0 & 1.0 & 0 & 0 & 1 & 0 & 0 & 1.0 & 0 & 0 & 1 \\
\hline $5 \mathrm{~min}$. & 1.5 & 2.25 & 0.414 & 0 & 1 & 0.317 & 0 & 1 & 0.317 & 0 & 1 & 0.317 \\
\hline $15 \mathrm{~min}$. & 2 & 0 & 0.083 & 0 & 1 & 0.317 & 0 & 2 & 0.083 & 0 & 1 & 0.317 \\
\hline $30 \mathrm{~min}$. & 1 & 0 & 0.317 & 2 & 2 & 0.564 & 0 & 1.5 & 0.157 & 1.5 & 1.5 & 1 \\
\hline $45 \mathrm{~min}$. & 1 & 0 & 0.317 & 2 & 1 & 0.655 & 2 & 2 & 0.564 & 3 & 3 & 0.656 \\
\hline $60 \mathrm{~min}$. & 1.5 & 1.5 & 1.0 & 0 & 1 & 0.317 & 0 & 1 & 0.317 & 2.5 & 2.5 & 1 \\
\hline $75 \mathrm{~min}$. & 2.5 & 2.5 & 0.317 & 0 & 0 & 1.0 & 0 & 0 & 1.0 & 0 & 0 & 1 \\
\hline $90 \mathrm{~min}$. & 0 & 0 & 1.0 & 0 & 0 & 1.0 & 0 & 0 & 1.0 & 0 & 0 & 1 \\
\hline
\end{tabular}




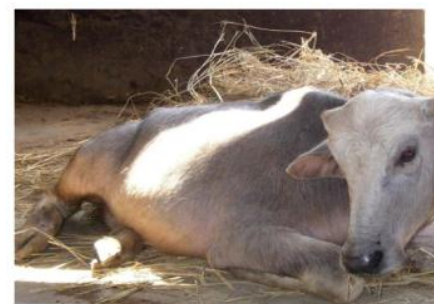

A

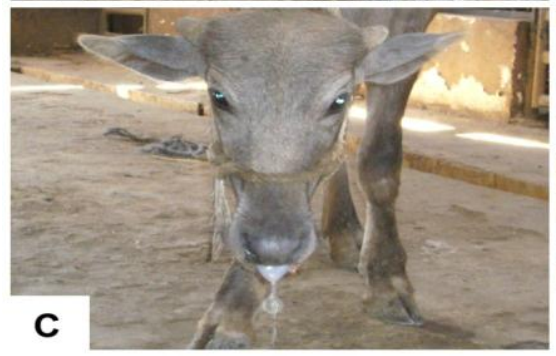

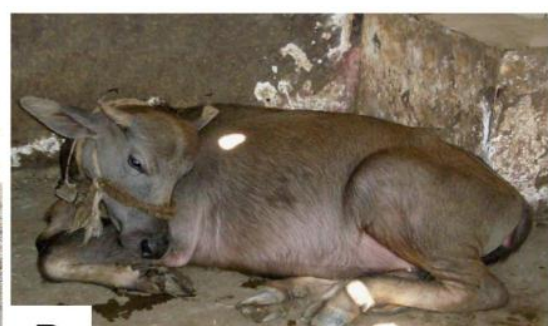

B

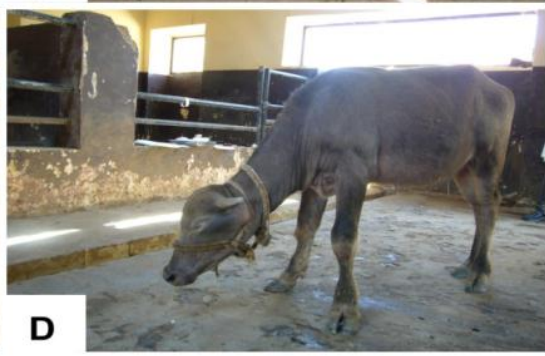

Fig. 7: Degree of sedation after injection of medetomidine (A\&C) and romifidine $(B \& D)$. Moderate sedation with sternal recumbency and milk fever position is seen in $A \& B$ ( 25 minutes post injection) while mild sedation is seen in $C \& D$ and the animals stand tired. Excessive salivation is observed (60 minutes post injection).

There was no significant difference in the degree of muscle relaxation (Table, 1) between the two groups ( $\mathrm{P}>0.05)$. Mild degree of muscle relaxation (moderate resistance to opening jaws and bending of limbs but with dropped head) was recorded in both groups during the period from 5-60 minutes after injection of medetomidine and romifidine, thereafter; the calves maintained their muscle tone fully. The degree of analgesia, as expressed by pedal and pinprick reflexes (Table, 1) was non significantly different in the two groups. Only mild depression of both reflexes was recorded allover the period from 5-60 minutes after injection of medetomidine and romifidine.

Although there was significant increase in serum glucose (Fig. 8) in both groups as compared to the baseline values, this increase was higher in group II after injection of romifidine than that in group I after injection of medetomidine. Group II showed significant increase in serum urea (Fig. 9) level at 15, 30, 60 and 90 minutes after romifidine injection while group I showed mild non significant increase. Serum AST (Fig. 10) and LDH (Fig. 11) increased significantly in both groups all over the study period. CPK (Fig. 12) increased significantly in group I at 30,60 and 90 minutes after medetomidine injection while greater significant increase was shown in group II all over the study period. 
Assiut Vet. Med. J. Vol. 53 No. 114 July 2007

Fig. (8): Serum glucose (Mean \pm SD) in buffalo calves injected with medetomidine (group I) and

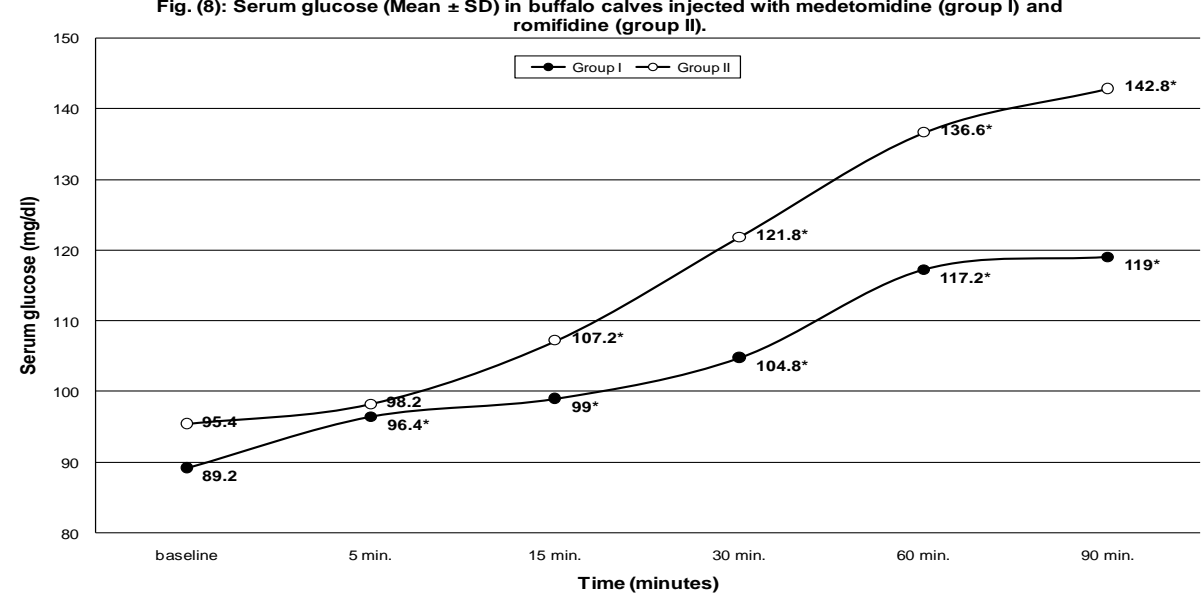

Fig. (9): Serum urea (Mean $\pm S D$ ) in buffalo calves injected with medetomidine (groupl) and

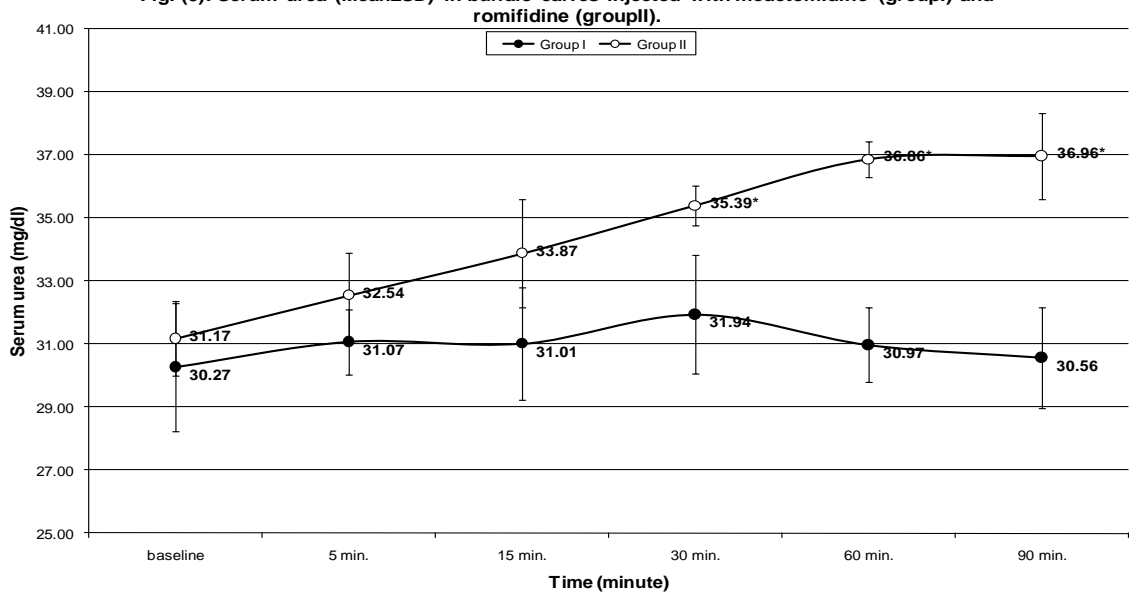

Fig. (10): Serum AST (Mean \pm SD) in buffalo calves injected with medetomidine (groupl) and

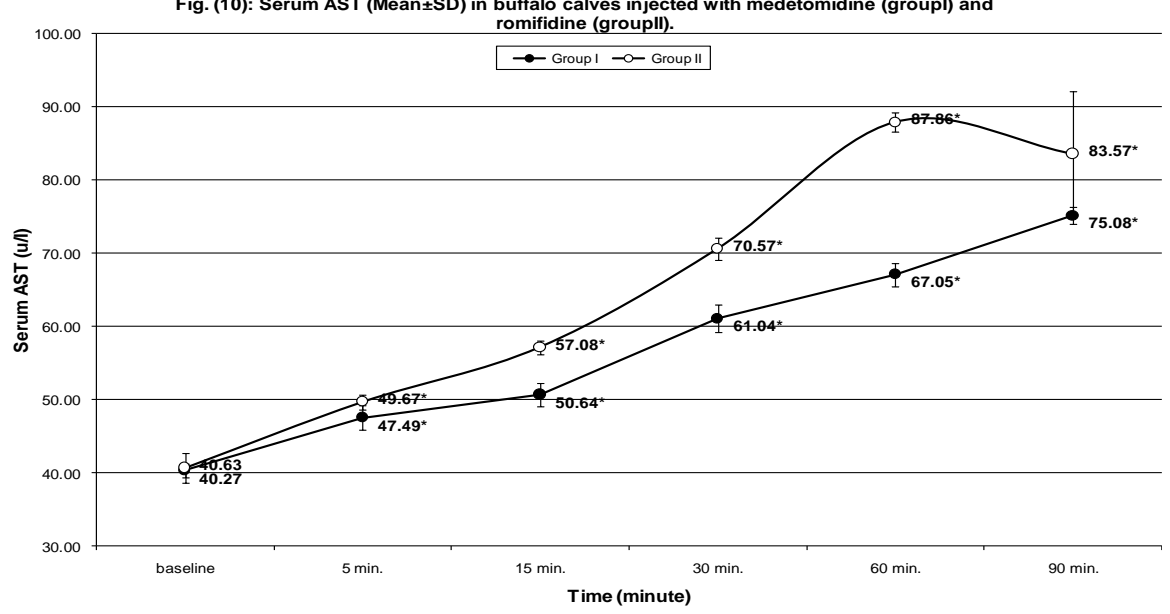



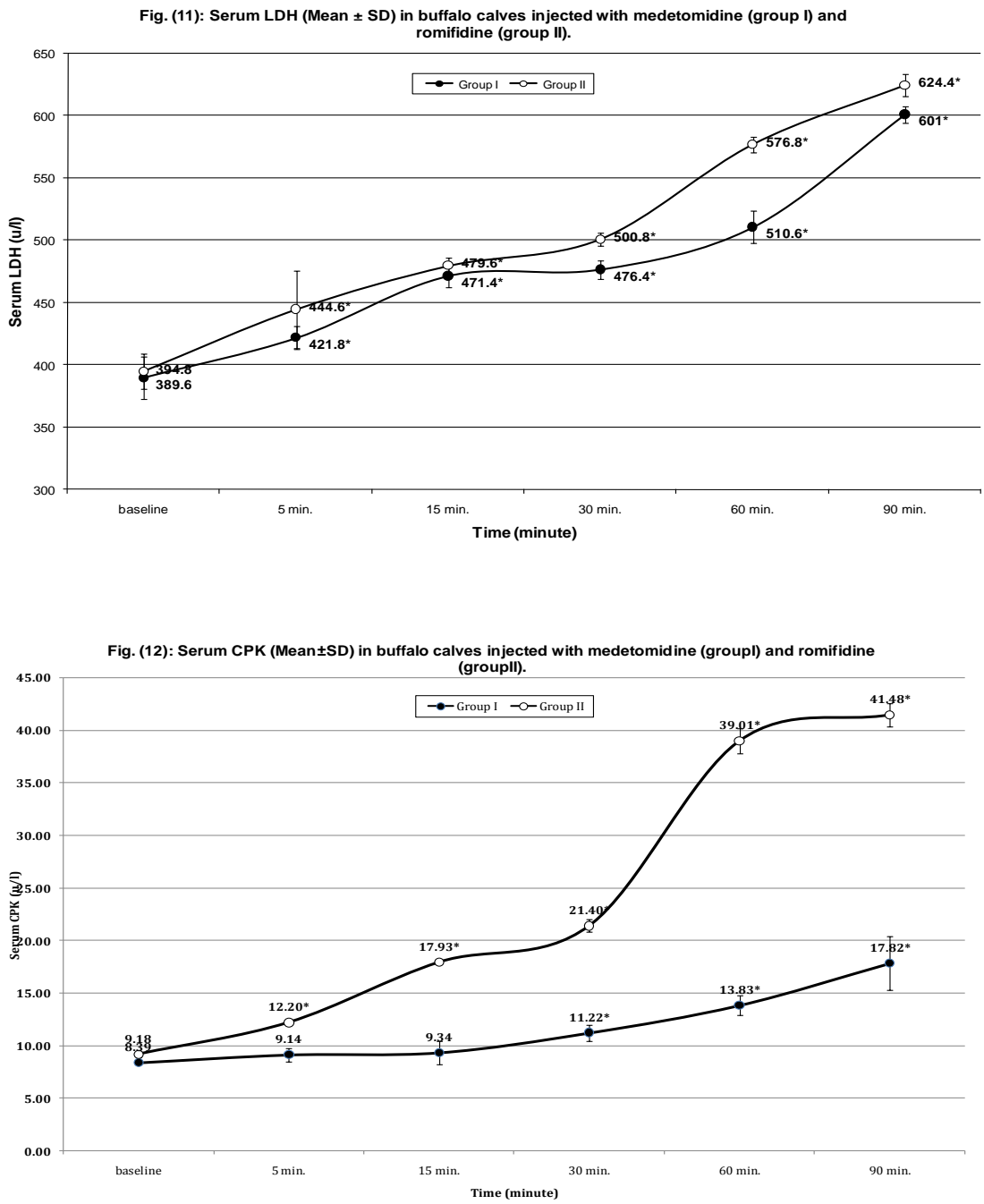

\section{DISCUSSION}

Alpha2-adrenoceptor agonists are used to produce sedation, analgesia, and muscle relaxation in sheep (Celly et al., 1997), horses (Freeman, Bowen, Bettschart-Wolfensbergery, Alibhai, and England, 2002; and Figueiredo, et al., 2005) and goats Kinjavdekar, et al., 2007).

The alpha-2 agonists can have marked effects on the cardiovascular system. These include bradycardia, an initial hypertension followed by hypotension, a decrease in cardiac output, and an increase in systemic vascular resistance (Freeman, et al., 2002). In this study, heart rate decreased significantly after injection of both 
medetomidine and romifidine in buffalo calves. The fall in heart rate after romifidine injection was greater than that after medetomidine injection as compared to the baseline values. Similarly, romifidine induced bradycardia, and decreased cardiac output in horses (Figueiredo, et al., 2005). Our result was also consistent with the findings of Singh, Amarpal, Kinjavdekar, Aithal, and Pratap, (2005) who found that injection of medetomidine alone markedly reduced heart rate when compared to medetomidine and ketamine in buffaloes. Westropp, et al. (2007) also stated that heart rate decreased after medetomidine administration in healthy cats. The significant fall in heart rate, in this study, had continued up to 75 minutes after injection of medetomidine, while it continued after romifidine injection allover the study period. This result was consistent with that of Freeman, et al. (2002) who stated that the cardiovascular effects of romifidine in horse are prolonged. Moreover Kinjavdekar, et al. (2006) demonstrated a significant reduction in heart rate soon after the administration of romifidine subarachnoidally in goats until the end of the observation period.

Sinus and AV block induced by alpha2-adrenoceptor agonists are often associated with bradycardia that may be attributed to decreased sympathetic outflow from the central nervous system and increased vagal tone (Bueno, Cornick-Seahorn, Seahorn, Hosgood, and Moore, 1999). ECG findings, in this study, showed that medetomidine injection induced marked bradycardia in buffalo calves indicated by prolongation of the R-R interval. Similarly, the ECG changes in goats administered with medetomidine $(0.01 \mathrm{mg} / \mathrm{kg}$ body wt) in the subarachnoid space showed bradycardia and prolongation of R-R interval and Q-T intervals (Kinjavdekar, Singh, Amarpal, Pawde, and Aithal, 1999). They added that the increase amplitude/duration of QRS complex indicates increased ventricular depolarization while increased amplitude of $\mathrm{T}$ wave may indicate myocardial hypoxia. The $\mathrm{P}$ wave amplitude, in this study, did not change by medetomidine injection which indicated that the atrial depolarization was not affected after the injection, a result that coincided with Singh, et al. (2005). However, the P wave morphology was changed after medetomidine and romifidine injection from biphasic (bifid) to monophasic. The heart rate began to return to its baseline value after 60 minutes post medetomidine injection and both $\mathrm{P}$ and $\mathrm{T}$ wave became biphasic and had returned to normal amplitudes. These changes suggested that the cardiac changes of medetomidine in buffalo calves continue for 60 minutes after injection and had returned to baseline afterwards. 
The ECG findings, in this work, showed normal sinus rhythm before injection of romifidine. However, romifidine injection produced bradycardia associated with first and second degree atrioventricular (AV) heart block. The AV block indicated that the impulses did not transmit from atria to ventricles due to more vagal stimulation induced by romifidine injection (Kinjavdekar, Aithal, Pawde, and Pratap, 2002). Similarly, romifidine was demonstrated to induce marked bradycardia and AV heart block in horses that was obliterated by administration of atropine sulphate, 5 minutes before injection (Gasthuys, Parmentier, Goossens, and De Moor, 1990). Our results conformed also with those reported earlier following subarachnoid injection of romifidine in goats in which the important ECG changes recorded were bradycardia, increased PR and QT intervals and increased amplitude of the T waves (Kinjavdekar, et al., 2006). The central sympatholytic effect of romifidine may be responsible for the atrioventricular heart block (Wagner, Muir, and Hinchcliff, 1991) while the bradycardia could be attributed to inhibition of sympathetic tone from CNS and vagal stimulation induced vasoconstriction (Ruffolo, Nichols, Stadel, and Hieble, 1993). Figueiredo, et al. (2005) added that second AV block occurred following the administration of romifidine and the incidence of arrhythmias declined as heart rate increased and signs of sedation decreased.

Alpha2-adrenoceptor agonists decrease respiratory rate and heart rate. Hypoventilation usually does not occur because the depth of breathing increases to maintain minute ventilation (Yamashita, Tsubakishita, Futaok, 2000; Freeman, et al., 2002). In this study, respiratory rate decreased significantly at 15, 30 and 45 minutes after medetomidine injection in group I, while it decreased significantly at 5, 15, 30, 45, 60 and 75 minutes after romifidine injection in group II. A previous study showed that romifidine caused reduced respiratory rate in horses (Figueiredo, et al., 2005). Moreover, rapid IV injection of alpha2 agonists without supplementary oxygen should be avoided whenever hypoxemia may be critical (Kastner, 2006). Yamashita, Wijayathilaka, Koshiro, Umar, Tagushi, and Muir, (2007) suggested also that medetomidine/ ketamine/ midazolam combination for total intravenous anesthesia in horses has considerable promise as an injectable technique that can be used to produce extended anesthesia under field conditions. They added that inspired air should be supplemented with oxygen to prevent hypoxemia.

Moderate sedation was recorded in the animals of this study after injection of medetomidine and romifidine. These animals showed sternal 
recumbency and took a position resemble to the milk fever position throughout the period from 15 - 60 minutes after injection, thereafter mild sedation was observed for another 15 minutes and the calves were standing tired and their heads were lowered. Likewise, Robertsona, and Taylor, (2004) stated that alpha2 agonists, primarily medetomidine, dexmedetomidine and originally xylazine are commonly used in cats for their sedative and anesthetic sparing properties. Our result conformed also with Figueiredo, et al. (2005) who stated that romifidine is a potent and selective alpha2 adrenoceptor agonist that produces sedation, muscle relaxation, reluctance to move, reduced responsiveness to environmental stimuli. Additionally, this result agreed also with Yamashita, Muir, Tsubakishita, Abrahamsen, Lerch, Hubbell, Bendarski, Skarda, Izumisawa, and Kotani, (2002); and Yamashita, et al. (2007) who reported that medetomidine has a high $\alpha 2$ adrenoceptor selectivity and produce sedative and analgesic effects at small doses in horses. In our study, the sedative effect started 5.8 minutes and 3 minutes after medetomidine and romifidine injection respectively while, the calves began to recover from sedation 108 minutes after romifidine sedation the time which was significantly longer than that after medetomidine sedation (71 minutes). Although the degree of sedation was moderate in the two groups without significant difference, romifidine induced longer slightly deeper sedation than did medetomidine based on the signs of sedation and responsiveness of the sedated calves to their environment. Only one animal from the five administered with medetomidine, in this study, showed a deeper degree of sedation than other animals. This calf was laterally recumbent and unable to sit without support for 60 minutes after medetomidine injection; thereafter it began to sit on sternal recumbent position for another 20 minutes.

Mild degree of muscle relaxation (moderate resistance to opening of jaws and bending of limbs but with dropped head) was recorded in both groups of our study during the period from 5-60 minutes after injection of medetomidine and romifidine without significant difference, thereafter; the calves maintained their muscle tone fully. Nevertheless, Freeman, and England, (2000); and Figueiredo, et al. (2005) reported that alpha2-adrenoceptor agonists produce excellent muscle relaxation of the muscles of the head, neck, and ears in horses followed by drooping of the head, ears, and lips. They explained that these effects are centrally mediated, are well correlated with degree of sedation, and have become widely accepted as objective methods for the assessment of the depth and duration of the sedation provided by alpha2-adrenoreceptor agonists. 
These authors did not practice any attempts to open the animal's jaws or bending limbs for assessment of degree of relaxation as we did in this study and although there was drooping in the head and neck, the degree of relaxation was expressed as mild according to the assessed parameters. Muscle relaxation was also reported in the study of Robertsona, and Taylor, (2004) in cats.

Analgesia is an important quality of alpha2 adrenoceptor agonists (England and Clarke 1996). In this study, only mild analgesia as expressed by mild depression in both pedal and pinprick reflexes was recorded during the period from 5-60 minutes after injection of medetomidine and romifidine in this study without significant difference. While, Figueiredo, et al. (2005) demonstrated that romifidine produced a significant increase of the latency time to hoof withdrawal in horses administered IV with romifidine. In agreement with our results, the results of Kinjavdekar, et al. (2006) indicated that romifidine is able to produce a mild to moderate degree of hindquarter analgesia after subarachnoid administration in goats. They added that the mechanism of analgesic action of subarachnoidally administered romifidine was probably due to the stimulation of $\alpha 2$ adrenoceptors at the spinal cord level. Molina, and Herrero, (2006) described also that the analgesic effectiveness of medetomidine, is either because its main place of action is supraspinal or because the effect is a result of an interaction of medetomidine-mediated antinociceptive activity at spinal and supraspinal sites.

Although there was a significant increase in serum glucose in both groups as compared to the baseline values, this increase was higher in group II after injection of romifidine than that in group I after injection of medetomidine. Similarly, Lyons (1997) reported that analgesia and anesthesia are usually followed by increased cortisone level which subsequently suppresses insulin release with subsequent increase in serum glucose level. Group II, in this study, showed significant increase in serum urea level at 15, 30, 60 and 90 minutes after romifidine injection while group I showed mild non significant increase. Serum AST and LDH showed significant increase in both groups all over the study period. CPK increased significantly in group I at 30, 60 and 90 minutes after medetomidine injection while greater significant increase was shown in group II all over the study period. These results were consistent with that of Raskallio, Vainio, and Karyalan (1990) who stated that the marked changes in the function of cardiac muscle involved a decrease in heart rate, cellular injury, and ultrastructural changes in the 
key subcellular organilles mediated in the form of leakage of cardiac enzymes (AST, LDH, and CPK).

On the basis of the results of the present study it could be concluded that medetomidine at the dose rate of $10 \mu \mathrm{g} / \mathrm{kg}$ and romifidine at the dose rate of $50 \mu \mathrm{g} / \mathrm{kg}$ produced only moderate degree of sedation, and mild degree of muscle relaxation and analgesia in buffalo calves. These figures are considered beneficial for safe investigation and clinical examination in these animals. Further restraint or conjunction with other local or general anesthetic is needed for surgical approaches. Medetomidine is considered superior to romifidine because the later induces prolonged cardiopulmonary depression which may be alarming, and also it induces comparatively higher serum levels of urea and cardiac enzymes.

\section{REFERENCES}

Bueno, A.C.; Cornick-Seahorn, J.; Seahorn, T.L.; Hosgood, G.; and Moore, R.M. (1999): Cardiopulmonary and sedative effects of intravenous administration of low doses of medetomidine and xylazine to adult horses. Am. J. Vet. Res., 60: 1371-1376.

Celly, C.S.; McDonell, W.N.; Young, S.S.; and Black, W.D. (1997): The comparative hypoxaemic effect of four alpha-2 adrenoceptor agonists (xylazine, romifidine, detomidine and medetomidine) in sheep. J. Vet. Pharm. Ther., 20: 464-471.

England, G.C. and Clarke, K.W. (1996): Alpha 2 adrenoceptor agonists in the horse: A review. Br. Vet. J., 152: 641-657.

Figueiredo, J.P.; Muir, W.W.; Smith, J. and Wolfrom, G.W. (2005): Sedative and analgesic effects of romifidine in horses. Intern. J. Appl. Res. Vet. Med., 3(3): 249-258.

Freeman, S.L. and England, G.C. (2000): Investigation of romifidine and detomidine for the clinical sedation of horses. Vet. Rec., 147: 507-511.

Freeman, S.L.; Bowen, I.M.; Bettschart-Wolfensbergery, R.; Alibhai, H.I.K. and England, G.C.W. (2002): Cardiovascular effects of romifidine in the standing horse. Research in Veterinary Science 72: 123-129.

Gasthuys, F.; Parmentier, D.; Goossens, L. and De Moor, A. (1990): A preliminary study on the effects of atropine sulphate on bradycardia and heart blocks during romifidine sedation in the horse. Vet. Res. Commun., 14(6): 489-502.

Gomez-Villamandos, R.J.; Redondo, J.I.; Martin, E.M.; Dominguez, J.M.; Granados, M.M.; Estepa, J.C.; Ruiz, I.; Aguilera, E. and 
Santisteban, J.M. (2005): Romifidine or medetomidine premedication before propofol-sevoflurane anaesthesia in dogs. J. Vet. Pharmacol. Ther., 28(5): 489-493.

Huber, M.; Neagu, I.; Braslasu, M.C.; Braslasu, E.D. and Joita, S. (2004): Electrocardiographical parameters in newborn calves. Revista Româna de Medicina Veterinara, 14 (3): 155-166.

Kastner, S.B. (2006): A2-agonists in sheep: a review. Vet. Anaesth. Analg., 33(2): 79-96.

Kinjavdekar, P.; Aithal, H.P.; Amarpal; Pawde, A.M.; Pratap, K. and Singh, G.R. (2006): Potential effect of romifidine with lidocaine administration in goats. Small Ruminant Research, 64: 293-304.

Kinjavdekar, P.; Aithal, H.P.; Pawde, A.M. and Pratap, K. (2002): Analgesic, sedative and haemodynamic effects of spinally administered romifidine in female goats. J. Vet. Med. A Physiol. Pathol. Clin. Med. 49(1):3-8.

Kinjavdekar, P.; Singh, G.R.; Amarpal; Aithal, H.P. and Pawde, A.M. (2007): Clinicophysiological effects of spinally administered ketamine and its combination with xylazine and medetomidine in healthy goats. Vet. Res. Commun., 8(1): 15-22.

Kinjavdekar, P.; Singh, G.R.; Amarpal; Pawde, A.M. and Aithal, H.P. (1999): Effects of subarachnoid xylazine and medetomidine on haemodynamics and ECG in goats. Zentralbl. Veterinarmed. $A$. 46(5): 271-275.

Lyons, F.M. (1997): Effects of clonidine on the pituitary hormonal response to pelvic surgery. Br. J. Anaesth., 78: 134-139.

Malm, S.; Strandberg, E.; Danell, B.; Audell, L.; Swenson, L. and Hedhammar, A. (2007): Impact of sedation method on the diagnosis of hip and elbow dysplasia in Swedish dogs. Prev. Vet. Med., 78(3-4): 196-209.

Molina, C. and Herrero, J.F. (2006): The influence of the time course of inflammation and spinalization on the antinociceptive activity of the $\alpha 2$-adrenoceptor agonist medetomidine. Europ. J. Pharmacol., 532: 50-60.

Pawde, A.M.; Amarpal, Kinjavdekar, P.; Aithal, H.P.; Pratap, K. and Bisht, G.S. (2000): Detomidine-diazepam-ketamine anesthesia in buffalo (Bubalus bubalis) calves. J. Vet. Med., 47: 175-181.

Raskallio, A.; Vainio, C. and Karyalan, M. (1990): The influence of atipamizole on the cardiovascular effects of detomidine in horses. J. Assoc. Vet. Anesth., 17: 50-53. 
Robertsona, S.A. and Taylor, P.M. (2004): Pain management in catsdpast, present and future. Part 2. Treatment of paind- Clinical pharmacology. J. Fel. Med. Surg., 6: 321-333.

Ruffolo, R.R.; Nichols, A.J.; Stadel, J.M. and Hieble, J.P. (1993): Pharmacologic and therapeutic applications of alpha 2-adrenoceptor subtypes. Annu. Rev. Pharmacol. Toxicol., 33: 243-279.

Sharma, A.K.; Kumar, N.; Dimri, U.; Hoque, M.; Maiti, S.K.; Gupta, O.P. and Shahi, A. (2004): Romifidine-Ketamine Anaesthesia in Atropine and Triflupromazine Pre-medicated Buffalo Calves. JAVM, A 51, 420-424.

Singh, V.; Amarpal; Kinjavdekar, P.; Aithal, H.P. and Pratap, K. (2005): Medetomidine with ketamine and bupivacaine for epidural analgesia in buffaloes. Vet. Res. Commun., 29(1): $1-18$.

Umar, M.A.; Yamashita, K.; Kushiro, T. and Muir, W.W. (2007): Evaluation of cardiovascular effects of total intravenous anesthesia with propofol or a combination of ketaminemedetomidine-propofol in horses. Am. J. Vet. Res., 68(2): 121127.

Wagner, A.E.; Muir, W.W. $3^{\text {rd }}$ and Hinchcliff, K.W. (1991): Cardiovascular effects of xylazine and detomidine in horses. Am. J. Vet. Res., 52: 651-657.

Westropp, J.L.; Kass, P.H. and Buffington, C.A. (2007): In vivo evaluation of alpha (2)-adrenoceptors in cats with idiopathic cystitis. Am. J. Vet. Res., 68(2): 203-207.

Yamashita, K.; Muir, W.W.; Tsubakishita, S.; Abrahamsen, E.; Lerch, P.; Hubbell, J.A.; Bendarski, R.M.; Skarda, R.T.; Izumisawa, $Y$. and Kotani, T. (2002): Clinical comparison of xylazine and medetomidine for premedication of horses. J. Am. Vet. Med. Assoc., 221: 1144-1149.

Yamashita, K.; Tsubakishita, S. and Futaok, S. (2000): Cardiovascular effects of medetomidine, detomidine and xylazine in horses. J. Vet. Med. Sci., 62: 1025-1032.

Yamashita, K.; Wijayathilaka, T.P.; Koshiro, T.; Umar, M.A.; Tagushi, K. and Muir, W.W. (2007): Anesthetic and cardiopulmonary effects of total intravenous anesthesia using a midazolam, ketamine, and medetomidine drug combination in horses. J. Vet. Med. Sci., 69(1): 7-13. 
Fig. 4: R-R interval in ECG tracings recorded from buffalo calves injected with medetomidine (group I) and romifidine (group II).

Fig. 5: Respiratory rate (Mean $\pm \mathrm{SD}$ ) in buffalo calves injected with medetomidine (group I) and romifidine (group II).

Fig. 6: Weak time, Down time and Recovery time (Mean \pm SD) in buffalo calves injected with medetomidine (group I) and romifidine (group II).

Fig. 8: Serum glucose (Mean $\pm \mathrm{SD})$ in buffalo calves injected with medetomidine (group I) and romifidine (group II).

Fig. 9: Serum urea (Mean \pm SD) in buffalo calves injected with medetomidine (group I) and romifidine (group II).

Fig. 10: Serum AST (Mean \pm SD) in buffalo calves injected with medetomidine (group I) and romifidine (group II).

Fig. 11: Serum LDH (Mean \pm SD) in buffalo calves injected with medetomidine (group I) and romifidine (group II).

Fig. 12: Serum CPK (Mean $\pm S D)$ in buffalo calves injected with medetomidine (group I) and romifidine (group II).

Fig. 2: Heart rate (Mean \pm SD) in buffalo calves injected with medetomidine (group I) and romifidine (group II).

(Kinjavdekar, et al., 2007). 